\title{
Factor Analysis of Academic Staff Satisfaction in Dire Dawa University, Ethiopia
}

\author{
Dawit Daniel Dando ${ }^{1, *}$, Getachew Liben Abate $^{2}$, Ashenafi Adugna Mola ${ }^{3}$ \\ ${ }^{1}$ Department of Statistics, Dire Dawa University, Dire Dawa, Ethiopia \\ ${ }^{2}$ Department of English Language and Literature, Dire Dawa University, Dire Dawa, Ethiopia \\ ${ }^{3}$ Department of Industrial Engineering, Dire Dawa University, Dire Dawa, Ethiopia
}

Email address:

davdan8@gmail.com (D. D. Dando)

${ }^{*}$ Corresponding author

\section{To cite this article:}

Dawit Daniel Dando, Getachew Liben Abate, Ashenafi Adugna Mola. Factor Analysis of Academic Staff Satisfaction in Dire Dawa University, Ethiopia. Science Journal of Education. Vol. 5, No. 2, 2017, pp. 71-81. doi: 10.11648/j.sjedu.20170502.16

Received: February 22, 2017; Accepted: March 9, 2017; Published: April 1, 2017

\begin{abstract}
Job satisfaction is defined as how people feel about their jobs, different aspects of their jobs and it is an emotion, a feeling and a matter of perception. This study was conducted to explore academic staff satisfaction with the university and to extract a set of factors from various dimensions used to measure satisfaction. A cross-sectional study on a sample of 150 academic staff selected using simple random sampling technique was conducted. Primary data was collected on teachinglearning, facility provision, benefits \& incentives, research undertakings, community engagement, interpersonal relationship and management of the university. Descriptive statistics together with factor analysis using principal component extraction via varimax rotation was used. The Kaiser-Meyer-Olkin measure of sampling adequacy and Barlett's test of sphericity was employed to check the sample size and sufficiency of correlation between the variables. Analysis of data revealed that the general satisfaction level of Academic staff in the university is $40 \%$. The results indicated higher satisfaction levels for teaching-learning, interpersonal relationship, management of the university with $74.6 \%, 69.7 \%$ and $74.8 \%$ respectively. The factor analysis identified four factors within teaching-learning, facility provision and research undertaking. It also identified two factors within benefits \& incentives, community engagement, interpersonal relationship and management of the university. Additionally the satisfaction level did not indicate variation across sex. Therefore, although satisfaction level for the academic staff increased from the previous academic year it is still moderate and requires further work. Additionally service quality of Dire Dawa University showed progress but the management and other stakeholders should focus on improving the facilities related with recreation, internet access, transportation and restrooms on buildings.
\end{abstract}

Keywords: Employee Satisfaction, Higher Institution, Dire Dawa, Ethiopia

\section{Introduction}

Job satisfaction is a construct that has been widely discussed and extensively examined in related fields such as organizational behavior, human resources management, administration and management of industrial and business organizations, psychology, sociology and education over the years. It is a generalized affective and cognitive orientation to all aspects of the job which simply means the extent of an individual's feeling about the job and the extent of an individual's satisfaction with a particular aspect of the job such as pay, pension arrangements, working hours and a host of others respectively. Many studies focusing on organizational behavior have given extensive consideration to motivation, employee job satisfaction and organizational performance which are all interdependent on one other [1]. Job satisfaction represents a combination of positive or negative feelings that workers have towards their work. It is a frequently studied subject in the work and organizational literature. This is mainly due to the fact that many experts believe that job satisfaction trends can affect labor market behavior and influence work productivity, work effort, employee absenteeism and staff turnover [2].

Job satisfaction is defined as how people feel about their 
jobs and different aspects of their jobs. Job satisfaction is an emotion, a feeling and a matter of perception. It results from an appraisal of an employee's experiences at work. Job satisfaction involves likes, dislikes, extrinsic and intrinsic needs. It is within employee's control and yet also beyond his or her control. Job satisfaction is a fit between what the organizations requires, what the employee is seeking and what the employee is receiving. The degree of fit will determine the extent to which the employee is satisfied. Job satisfaction is a complex concept and difficult to measure objectively, because understanding the nature of job satisfaction is not easy [3].

One of the determinants of success of a firm is how the customers perceive the resulting service quality, as this is the key driver of perceived value. It is the perceived value which determines customer satisfaction. Firms including universities begin to track their customers' satisfaction through their level of service quality. The most widely used model to measure perceived service quality was developed by Parasuraman known as SERVQUAL [4]. According to this model, five dimensions of service quality are: Tangibles, Reliability, Responsiveness, Assurance and Empathy. "SERVQUAL" model developed by Parasuraman, Zeithaml and Berry were the most commonly used model and had been widely used in almost all the service organizations [5] [6]. It listed ten determinants of service quality that can be generalized to any type of service. The ten dimensions were then regrouped in the well-known five dimensions which include assurance, empathy, reliability, responsiveness and tangibility. Therefore, a modified version of the instrument as adapted by Ijaz, is used to measure the satisfaction level of academic staff in Dire Dwa university and at the same time to evaluate the service quality of this university based on all its clients perceptions.

\section{Statement of the Problem}

Ethiopia is transforming its higher education system by exerting its effort on the sector to enable it undergo enormous growth in recent years. Evidence from Ministry of Education suggest that both the number of higher education institutions and their intake capacity is rapidly increasing [7]. However, this increase in the gross enrolment rate put challenge on the overall quality of education [8]. Considering this the Ministry of Education is currently engaged on reforming the country's higher education system. This required measures including establishing supporting agencies such as the Higher Education Relevance and Quality Agency (HERQA), and the Educational Quality Improvement Programme (EQUIP) which are responsible for assuring quality of the education system.

Many educational institutions or universities including those in Ethiopia, begin to track their customers' satisfaction through measuring their level of service quality perceived by their customers as customer satisfaction is a new approach in an organization which emphasizes customer-oriented management. Evaluating customer satisfaction involves a prompt and objective feedback about clients ${ }^{\text {ee }}$ alternatives and expectations. In this regard, institution's performance might be assessed according to satisfaction level which shows the strong and the weak points of an organization. In the competitive world, customer satisfaction is considered as the fundamental of success.

Dire Dawa University, as one of governmental institutions in the country, is engaged on its activities such as teachinglearning, enhancing research, knowledge transfer, and community service in accordance to the country's demand. Considering this, and as part of the continuing effort to improve its services, the University is seeking information in every academic year about the quality of its service through continuous customer satisfaction study of which academic staff satisfaction assessment is one. The purpose of this study is to investigate the satisfaction level of academic staff of Dire Dawa University in 2015/16. In doing so we can investigate the satisfaction level of industries in relation to the service quality of the university

\section{Literature Review}

\subsection{Job Satisfaction}

Various researchers have defined job satisfaction in various manners. It is the sense of achievement and arrogance felt by employees who get pleasure from their employment and complete it well. Or it could define as an encouraging emotional condition resulting from the work [9]. Similarly an individual common thought toward his job is also termed as job satisfaction. The attitude can be positive or negative. The individuals who have positive attitude towards their jobs are more satisfied than the individuals who have negative attitude. It can be said that the individuals are dissatisfied with their jobs that have negative attitude towards it.

Job satisfaction is a very essential concept in any wok setting. Because the productivity of human resources depends upon their satisfaction level and satisfied recruits remain within the organization for longer time, while in case of dissatisfaction productivity will be lower and individuals are more inclined to leave the job.

In the same way Lawler defines that job satisfaction has only one-dimension. Employees are either pleased or unpleased with their work means that if they are satisfied with their work they will be happy and if they are unsatisfied they will be unhappy. But other scholars as Smith, Kendall and Hulin described that job satisfaction is a multidimensional concept, there can be many factors that can make an employee more or less satisfied with the work as someone might be extra satisfied with salary but could be least satisfied with supervisor behavior or availability of promotion opportunities in an organization [10].

There are various factors that influence the job satisfaction intensity of the employees such as pay, promotion opportunities, and relationship with colleagues, fringe benefits, working environment and recognition [11]. If someone is satisfied with even one of the dimension it doesn't meant that he is satisfied with all other dimensions as 
well. For example if a teacher is satisfied with the working environment it doesn't means he is also satisfied with the salary package that he or she obtained after one month. Hence either provision of only one factor cannot guarantee satisfaction of employee from job provision of all factors is crucial for employee job satisfaction.

Moreover, Hunjra described that high level of job satisfaction also leads toward the low rate of absenteeism and turnover. In other words it can be said if someone is satisfied with his job then he will be more regular and punctual and loyal in performing his job tasks. This regularity and punctuality is also critical for university teachers [11]. Therefore, the concept of satisfaction has great importance at the education sector because students are one of the precious assets of our society [12]. So it is necessary that its academic staff must be satisfied with their daily work so that they can perform their duties with dedication.

Generally job satisfaction can be defined as a positive or negative feeling that the workers feel about their work. It is the satisfaction of employees about the general aspects of job like pay, promotion, relationship with management, job itself, and progression in the job etc. Definition of job satisfaction is "the sense of achievement and arrogance felt by employees who get pleasure from their employment and complete it well". According to this definition it is the feeling of accomplishment that one's feel after the completion of his work.

\subsection{Determinants of Job Satisfaction at Higher Education}

Various researches have been conducted to find out the factors that impact level of job satisfaction in an organization as various researchers have quoted their views in different manner. According to Noordin and Jusoff the behavior of the academic staff is affected by the working environment that must be safe and healthy, career progression, administration support, salary, work teams, peers and the job itself. Along with these factors they also need autonomy in their decisions because making decisions independently have great importance and if universities are not giving importance to their employees then they may lose sense of owing the decisions and working accordingly [13].

Similarly, Briggs and Richardson quoted that academic staff would feel demoralized and devalued if they are not allowed to take part in decision making process. Ultimately this thing leads toward low motivation and satisfaction. It may leads toward negative consequences like decrease in productivity, turnover among the potential employees, deliberate absenteeism, lack of interest, lethargy and low performance at the work place [14]. According to them it may result in lose-lose situation which is ultimately harmful for the health of any organization.

On the other hand, Siddique indicated that salaries, fringe benefits, security of service, chance of promotion and social status are some factors that have relationship with the job satisfaction of the teachers [12]. Some of them have significant while other have insignificant relation with the dependent variable that is job satisfaction.
In the same way job satisfaction has a significant and clear relationship with the pay, promotion, working conditions, fringe benefits, support of research, gender and support of teaching, as suggested by Santhapparaj \& Alam [15]. Work itself, supervision, salary, working conditions, companies' policies and procedures, opportunities of promotion and coworkers are variables indicated by Alam that have considerable association with the job satisfaction at work place [15].

In line to this, Smith also described in their "job description index" that working condition, coworkers, pay, promotion opportunities, supervision and work itself are some factors that affect the satisfaction intensity of the teachers along with the above factors discussed by the other researchers [16]. In contrast to this, Lacy \& Sheehan identified that teaching, job security, promotion prospects, academic freedom, and management are variables of job satisfaction [17]. These variables may help to indicate the satisfaction level of academic staff. On the other hand Bayram found that burnout, stress and depression have a negative impact on the job satisfaction. Job satisfaction may decrease in the presence of these which lead towards the absenteeism and turnover.

\subsection{Customers' Satisfaction}

\subsubsection{Satisfaction and Its Implications}

In a competitive marketplace, where organizations vie for customers, client satisfaction becomes an important differentiator of marketing strategy. Customer satisfaction largely depends on the degree with which a product supplied by an organization meets or surpasses customer expectation. By measuring customer satisfaction, organizations are able to get indication of how successful they actually are in providing products to the market. Customer satisfaction is an important antecedent of loyalty. A positive impact of satisfaction is reported upon purchase behavior, repurchase intent, positive word-of mouth, customer retention and the continuous use of provided service [18].

Consumer satisfaction has been a popular topic in marketing. The associated literature can be divided into three broad topics: the first determines the antecedents of satisfaction, the second explores the relationship between consumer expectations and appraisals of performance, and the third and most recent category evaluates the consequences of consumer satisfaction for purchase decisions, sales, and firm profitability.

\subsubsection{Satisfaction Measurement}

The aim of the marketing concept holds that the goal of the organizations is to satisfy its customers and publics. Although many organizations have adopted this concept, many have failed in assessing and evaluating the consumers' satisfaction level. Instead of directly evaluating satisfaction, they refer to sales, enrollment, attendance and other variables to measure it. Tourangeau and Rasinski suggested a process through which individuals arrive and report their satisfaction, which involves at least five types 
of operations: interpreting the survey question, accessing relevant information about the organization from memory, weighing the information according to its relevance and importance, summarizing the information to an implicit judgment, and translating that implicit judgment into the given response format [19].

\subsubsection{Service Quality and Service Quality Assessment}

Marketers perceive service quality as the level of service needed to make it acceptable in the market place. For customers, service quality is the level of service required to satisfy their needs. Unlike products, service quality is evaluated by customers not only by the core service but also by the service experience. Andreassen and Lindestad verified that corporate image has a strong influence on customer satisfaction, especially if the customer has little knowledge about the service [18]. Consumers regard the image of the brand or the corporation as indicative of the quality of the products or services of that brand. Moreover, service brands with a positive image reinforce the perception of quality for all the services provided. Service quality is usually defined as the result of the comparison between perceived and expected service in either of the following perspectives: the Nordic defines service quality as a function of "technical" (what the customer gets) and "functional" (how the service is delivered) quality. The American perspective defines service quality as the discrepancy between expected and perceived service through five dimensions [5].

\section{Methodology}

\subsection{Study Design}

The study used a cross-sectional design on academic staff of the Dire Dawa University from June 04 to 25, 2015/16. Respondents were from all five colleges (College of Business and Economics, College of Natural and Computational Sciences, College of Health and Medical Sciences, College of Social Sciences \& Humanities, College of Law) and Technology Institute of the University.

\subsection{Sampling Design and Techniques}

The study respondents' were sampled from five different colleges and one institute. There were a total of 604 academic staff in $2015 / 16$ at the university. Estimated proportion of satisfaction levels for academic staff were obtained from the 2014/15 baseline satisfaction survey result and were used for sample size calculations.

Using 95\% confidence level, two percent margin of error and a total of 604 academic staff at the university the calculated sample size was 150 . The formula below was used to determine the sample size [20]:

$$
n=\frac{Z_{\alpha / 2}^{2} p q}{d^{2}}
$$

Where $Z_{\alpha / 2}=1.96$, (p) proportion of satisfaction of staff and (d) margin of error used are the figures mentioned above. The estimated sample size was proportionally allocated to their respective departments and final respondents were selected using simple random sampling technique. A list of both academic staff was obtained from Human Resource Directorate of the University for sampling purpose.

\subsection{Study Variables}

Academic staff satisfaction measures are related to teaching and learning, facilities, benefits and incentives, research undertakings, community engagement, academics' interpersonal relationship and management of the university.

\subsection{Data Collection Method}

The study used primary data collected from academic staff of the various colleges and Institute of the university. Data was collected by eight academic staff from various colleges of the university with close supervision of the researchers. Quantitative data was collected using selfadministered questionnaire with a five item lickert scale. For ease of presentation categories were merged and presented with three scale items as 'Satisfied', 'Not satisfied' and 'Neutral'. Additionally qualitative data was collected using interview.

\subsection{Method of Data Analysis}

Data was fed into IBM SPSS 21.0 with close supervision of the researchers after which data cleaning was conducted throughout the variables. The statistical validity and reliability of items on the questionnaire was checked using Cronbach-alpha and the results were all above 0.8 indicating an acceptable threshold. An exploratory factor analysis using a principal component extraction method with varimax rotation was conducted to assess the underlying structure for the satisfaction items of teaching \& learning, facility, benefits \& incentives, research undertakings, community engagement, interpersonal relationship and management of the university. The KaiserMeyer-Olkin measure of sampling adequacy was used to test whether the data were suitable for the analysis. Similarly, Barlett's test of sphericity was employed to check for sufficiency of correlation between the variables to proceed with the analysis. Finally the Kaiser-Guttman criterion of eigenvalues greater than 1.0 was used for retention.

\section{Results and Discussion}

As presented in Figure 1 below the descriptive result on academic rank of the university showed that more than half $(55.65 \%)$ of the academic staff are lecturers followed by $30.43 \%$ Graduate Assistant II and with the least number of assistant professors (1.74\%). 


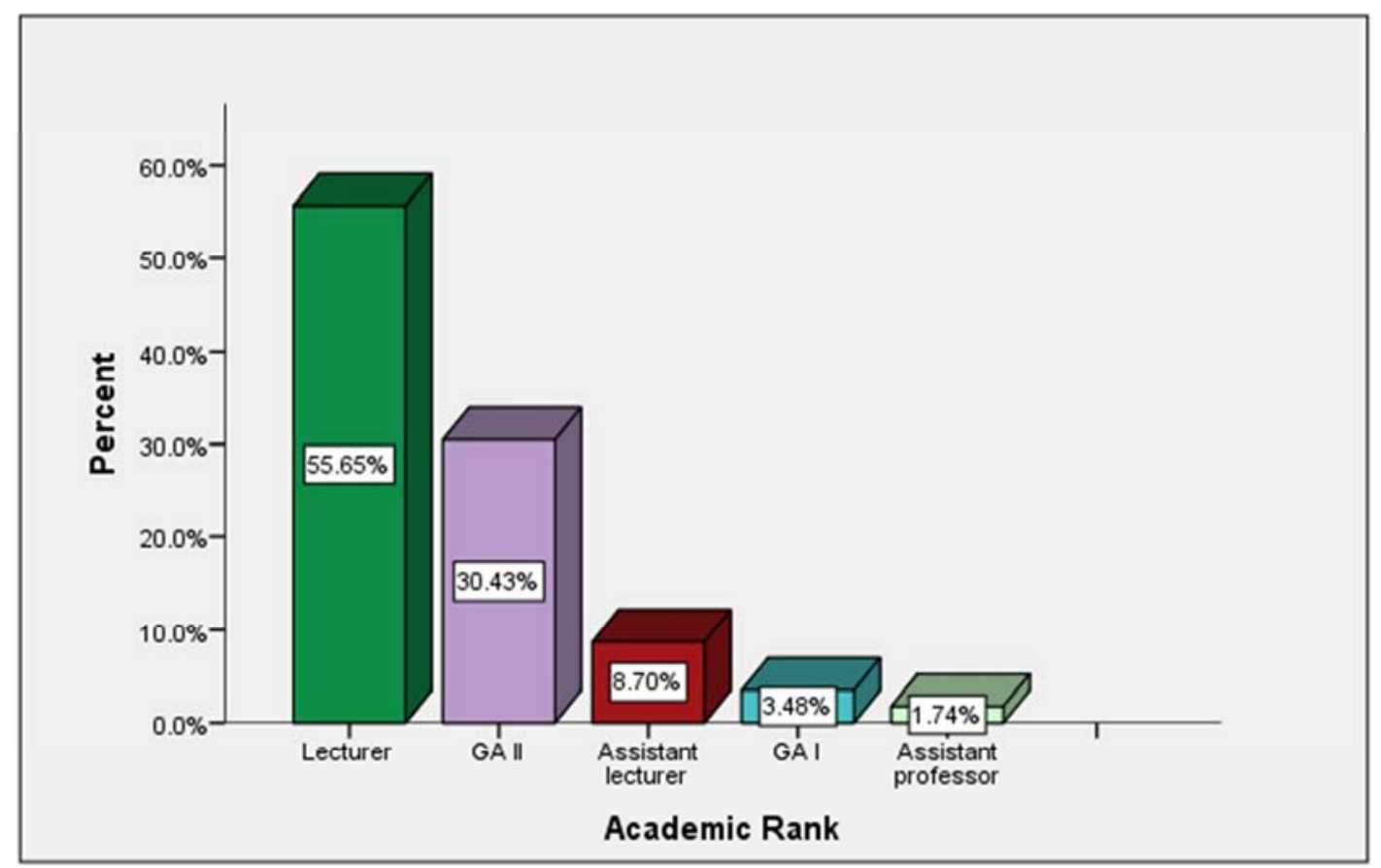

Figure 1. Academic rank profile of Dire Dawa University, Dire Dawa Ethiopia, 2015/16.

\subsection{Academic Staff Satisfaction}

The indicators used to measure satisfaction of the administration staff are mainly related to teaching and learning, facilities, benefits \& incentives, research \& community engagement, academics' interaction with colleagues, academics' view on management \& leadership.

\subsubsection{Teaching and Learning}

The result in table 1 below presents academic staff satisfaction with the teaching-learning where $82(69.5 \%)$ and $80(68.4 \%)$ were satisfied with course delivery and examination schedule respectively. Additionally 46 (39.3\%) were satisfied with the importance attached to the teaching-learning for promotion. The highest dissatisfaction was due to work environment and resource for teaching-learning $56 \quad(47.9 \%)$ and $52 \quad(44.8 \%)$ respectively.

Table 1. Academic staff satisfaction with teaching and learning in DDU, Dire Dawa Ethiopia, 2015/16.

\begin{tabular}{|c|c|c|c|c|}
\hline & & Satisfied & Indifferent & Not satisfied \\
\hline & & $\mathbf{n}(\%)$ & $\mathbf{n}(\%)$ & $\mathbf{n}(\%)$ \\
\hline 1 & work environment & $28(23.9)$ & $33(28.2)$ & $56(47.9)$ \\
\hline 2 & Program evaluation, curriculum development and review procedure & $39(33.6)$ & $48(41.4)$ & $29(25)$ \\
\hline 4 & Resource for teaching and learning & $34(29.3)$ & $30(25.9)$ & $52(44.8)$ \\
\hline 5 & Examination schedule & $80(68.4)$ & $24(20.5)$ & $13(11.1)$ \\
\hline 6 & Class schedule & $88(74.6)$ & $20(16.9)$ & $10(8.5)$ \\
\hline 8 & Committee assignment & $58(50)$ & $38(32.8)$ & $20(17.2)$ \\
\hline 9 & Academic calendar & $70(59.3)$ & $29(24.6)$ & $19(16.1)$ \\
\hline 10 & Importance attached to teaching for promotion & $46(39.3)$ & $41(35)$ & $(25.6)$ \\
\hline
\end{tabular}

\subsubsection{Facilities}

Academic staff satisfaction with the facilities of the university is presented in table 2 below where more than half, $71(63.4 \%)$, are satisfied with computer facility (either personal laptop or office desktop). 45 (39.5\%) were also satisfied with the stationary provided regularly. In opposite to this more than half, $80(73.4 \%), 71(62.3 \%), 74(66.1 \%)$ are not satisfied with internet service, recreational facilities and rest rooms in their office buildings.

Table 2. Academic staff satisfaction with facilities in DDU, Ethiopia, 2015/16.

\begin{tabular}{|c|c|c|c|c|}
\hline & & Satisfied & Indifferent & Not satisfied \\
\hline & & $\mathbf{n}(\%)$ & $\mathbf{n}(\%)$ & $n(\%)$ \\
\hline 1 & Availability of Stationary for teaching and learning & $45(39.5)$ & $30(26.3)$ & $39(34.2)$ \\
\hline
\end{tabular}




\begin{tabular}{lllll}
\hline & & Satisfied & Indifferent & Not satisfied \\
\hline & & $\mathbf{n ( \% )}$ & $\mathbf{n ( \% )}$ & n(\%) \\
\hline 2 & Availability of computers for the academic staffs & $71(63.4)$ & $13(11.6)$ & $28(25)$ \\
3 & Personal or shared office & $35(31)$ & $34(30.1)$ & $44(38.9)$ \\
4 & Availability of office furniture & $41(36.9)$ & $29(26.1)$ & $41(36.9)$ \\
5 & Availability of office janitors & $40(35.4)$ & $29(25.7)$ & $44(38.9)$ \\
6 & Availability of rest rooms & $19(17)$ & $19(17)$ & $74(66.1)$ \\
7 & Transportation facility & $19(16.8)$ & $27(23.9)$ & $67(59.3)$ \\
8 & Availability of repair and technical assistant & $31(27.4)$ & $30(26.5)$ & $52(46)$ \\
9 & Availability of recreation facilities & $21(18.4)$ & $22(19.9)$ & $71(62.3)$ \\
10 & Availability of internet access & $14(12.8)$ & $15(13.8)$ & $80(73.4)$ \\
\hline
\end{tabular}

\subsubsection{Research Undertaking}

Academic staff view of the university's research work is presented in Table 3 below. Nearly half of the staff 52 $(47.3 \%)$ are not satisfied with the research undertaking culture in the university. More than a quarter, $40(37.4 \%)$ and $32(29 \%)$, of the staff are satisfied with research/project proposal evaluation/approval procedure and the publication opportunities present in the university. Another measure where nearly half of the staff showed dissatisfaction is in equipment available to research and funds available to attend research workshop where $50(45.9 \%)$ and $50(46.3 \%)$ responded 'Not satisfied'.

Table 3. Academic staff satisfaction with research undertaking in DDU, Dire Dawa Ethiopia, 2015/16.

\begin{tabular}{|c|c|c|c|c|}
\hline & & Satisfied & Indifferent & Not satisfied \\
\hline & & $\mathbf{n}(\%)$ & $n(\%)$ & $\mathbf{n}(\%)$ \\
\hline 1 & Research undertaking culture & $27(24.5)$ & $31(28.2)$ & $52(47.3)$ \\
\hline 2 & Strategic thematic areas identification procedure & $28(25.7)$ & $43(39.4)$ & $38(34.9)$ \\
\hline 3 & Number of research workshops in the university & $23(21.1)$ & $48(44)$ & $38(34.9)$ \\
\hline 4 & Research and project proposal evaluation and approval & $40(37.4)$ & $40(37.4)$ & $27(25.2$ \\
\hline 5 & Research and project financing procedure & $25(22.9)$ & $38(34.9)$ & $46(42.2)$ \\
\hline 6 & Monitoring and evaluation of the projects & $25(22.9)$ & $48(44)$ & $36(33)$ \\
\hline 8 & Publication procedure & $26(24.1)$ & $52(48.1)$ & $30(27.8)$ \\
\hline 9 & Availability of research assistants & $25(23.1)$ & $39(36.1)$ & $44(40.7)$ \\
\hline 10 & Research capacity building workshops & $23(21.5)$ & $38(35.5)$ & $46(43)$ \\
\hline 11 & Time available to carry out your research duties & $32(29.4)$ & $39(35.8)$ & $38(34.9)$ \\
\hline 12 & Availability of equipment for research (e.g. Laboratory...) & $16(14.7)$ & $43(39.4)$ & $50(45.9)$ \\
\hline 13 & Availability of funds to attend professional conferences & $18(16.7)$ & $40(37)$ & $50(46.3)$ \\
\hline 14 & Importance attached to research for promotion & $29(26.6)$ & $38(34.9)$ & $42 \quad(38.5)$ \\
\hline
\end{tabular}

\subsubsection{Community Engagement}

Academic staff view of the university's community engagement is presented in Table 4 below. More than a quarter of the staff 37 (33.9) are satisfied with the Community engagement proposal evaluation/ approval procedure. In terms of incentive reward, half 52 (48.1\%), of the staff are not satisfied with incentive and reward scheme for community engagement. Another measure where the staff showed dissatisfaction is financing procedure where $42(38.2 \%)$ reported as 'Not satisfied'. In terms of importance attached to community engagement 42 (38.55) are not satisfied and prefer more weight and attention to community service.

Table 4. Academic staff satisfaction with community engagement by DDU, Dire Dawa Ethiopia, 2015/16.

\begin{tabular}{lllll}
\hline & & Satisfied (\%) & Indifferent & Not satisfied \\
\hline & & $\mathbf{n}(\%)$ & $\mathbf{n}(\%)$ & $\mathbf{n}(\%)$ \\
\hline 1 & Community engagement culture in the university & $36(33)$ & $31(28.4)$ & $42(38.5)$ \\
2 & Communication with local stakeholders to identify needs & $32(29.6)$ & $34(31.5)$ & $42(38.9)$ \\
3 & Thematic area identification procedure & $37(33.9)$ & $39(35.8)$ & $33(30.3)$ \\
4 & Community engagement proposal evaluation and approval procedure & $37(33.9)$ & $35(32.1)$ & $37(33.9)$ \\
5 & Community engagement financing procedure & $28(25.7)$ & $37(33.9)$ & $44(40.4)$ \\
6 & Follow up and support given & $29(26.4)$ & $39(35.5)$ & $42(38.2)$ \\
7 & Incentive and reward scheme for community engagement & $28(25.9)$ & $28(25.9)$ & $52(48.1)$ \\
8 & Importance attached to community engagement for promotion & $31(28.4)$ & $36(33)$ & $42(38.5)$ \\
\hline
\end{tabular}

\subsubsection{Academics' Interpersonal Relationship}

Another measure which determines the staffs' general satisfaction is the interpersonal relationship with their colleague. The result presented in table 5 below revealed that most of them $76(69.75)$ and $72(66.1 \%)$ are satisfied about their relationship with their colleague and the support they obtain from them respectively. The lowered satisfaction is the support staff get from administrative personnel outside the department, 40 (36.7\%). More than half, 69 (63.35), are also content with clerical support in their respective department. 
Table 5. Academic staff satisfaction with interpersonal relationship in DDU, Dire Dawa Ethiopia, 2015/16.

\begin{tabular}{|c|c|c|c|c|}
\hline & & Satisfied & Indifferent & Not satisfied \\
\hline & & $\mathbf{n}(\%)$ & $\mathbf{n}(\%)$ & $\mathbf{n}(\%)$ \\
\hline 1 & Personal relationship with colleagues & $76(69.7)$ & $22(20.2)$ & $11(10.1)$ \\
\hline 2 & Support from colleagues for the activities you carry out & $72(66.1)$ & $28(25.7)$ & $9(8.3)$ \\
\hline 3 & The academic communication among colleagues & $68(62.4)$ & $27(24.8)$ & $14(12.8)$ \\
\hline 4 & Clerical support in your department & $69(63.3)$ & $21(19.3)$ & $19(17.4)$ \\
\hline 5 & Support from administrative personnel outside your department & $40(36.7)$ & $31 \quad(29.4)$ & 37 (33.9) \\
\hline
\end{tabular}

\subsubsection{Management of the University}

Table 6 presents academic staff view of management and leadership of the university. It appears that academic staff are more satisfied with the lower leadership. Most of the staff 80 $(74.8 \%)$ and $77(71.3 \%)$ are satisfied about the relationship and support they get from their department head respectively.
$41(38.3 \%)$ of the academics are satisfied with the quality of leadership in the university but 47 (43.15) are not satisfied with the communication between management and staff. Additionally $41(38.3 \%)$ are not satisfied with the quality of administration staff.

Table 6. Academic staff satisfaction with management of the university, Dire Dawa Ethiopia, 2015/16.

\begin{tabular}{lllll}
\hline & & Satisfied & Indifferent & Not satisfied \\
\hline & & $\mathbf{n ( \% )}$ & $\mathbf{n ( \% )}$ & $\mathbf{n ( \% )}$ \\
\hline 1 & Quality of leadership in the university & $41(38.3)$ & $24(22.4)$ & $42(39.3)$ \\
2 & Communication between university management staff & $32(29.4)$ & $30(27.5)$ & $47(43.1)$ \\
3 & Quality of administrative staffs & $37(34.6)$ & $29(27.1)$ & $41(38.3)$ \\
4 & Quality of leadership in the department & $55(50.9)$ & $36(33.3)$ & $17(15.7)$ \\
5 & Your relationship with the department head & $80(74.8)$ & $22(20.6)$ & $5(4.7)$ \\
6 & Support you get from your department head & $77(71.3)$ & $19(17.6)$ & $(11.1)$ \\
\hline
\end{tabular}

\subsection{Extracted Factors on Academic Staff Satisfaction}

An exploratory factor analysis using a principal component extraction method with varimax rotation was conducted to assess the underlying structure for the satisfaction measures of teaching \& learning, Benefits \& incentives, facilities, research undertakings, community engagement, interpersonal relationship and management of the university. The KaiserMeyer-Olkin measure of sampling adequacy for all of the factors was above 0.8 indicating that the present data were suitable for the factor analysis. Similarly, Barlett's test of sphericity was significant $(\mathrm{p}<.001)$, indicating sufficient correlation between the variables in all of the satisfaction dimensions. Finally Kaiser-Guttman retention criterion of eigenvalues greater than 1.0 was used and items with loadings less than 0.40 are omitted to improve clarity.

\subsubsection{Teaching and Learning}

As presented in Table 7 below a total of four-factor solution provided the clearest extraction. These four factors accounted for $61.4 \%$ of the total variance and communality estimates were fairly high for each of the 9 items with a range of 0.5 to 0.77 . After rotation the first factor accounted for $17.76 \%$, the second factor for $15.56 \%$, the third factor for $14.4 \%$ and lastly the fourth factor for $13.76 \%$ of the variance. Accordingly items from one to three, from five to six and from seven to nine are under factor one, three and four respectively. Factor two consisted only course delivery schedule.

Table 7. Factor loadings for rotated factors of teaching \& learning, DDU 2015/16.

\begin{tabular}{|c|c|c|c|c|c|c|}
\hline & & \multicolumn{4}{|c|}{ Factor Loadings } & \multirow{2}{*}{ Communality } \\
\hline & & Factor 1 & Factor 2 & Factor 3 & Factor 4 & \\
\hline 1 & work environment & 0.76 & & & & 0.66 \\
\hline 2 & Resource for teaching and learning & 0.65 & & & & 0.60 \\
\hline 3 & Program evaluation, curriculum development and review procedure & 0.49 & 0.43 & & & 0.50 \\
\hline 4 & Course delivery schedule & & 0.83 & & & 0.77 \\
\hline 5 & Examination schedule & & & 0.55 & & 0.5 \\
\hline 6 & Invigilation assignment & & & 0.66 & & 0.52 \\
\hline 7 & Committee assignment & & & 0.56 & 0.64 & 0.76 \\
\hline 8 & Academic calendar & & & & 0.63 & 0.53 \\
\hline \multirow[t]{3}{*}{9} & Importance attached to teaching for promotion & 0.53 & & & 0.56 & 0.67 \\
\hline & Eigen values & 1.78 & 1.56 & 1.45 & 1.41 & \\
\hline & Percentage of variance & 17.76 & 15.56 & 14.4 & 13.76 & \\
\hline
\end{tabular}

\subsubsection{Benefits and Incentives}

As presented below (Table 8) two factors each accounting for $39.28 \%$ and $32.43 \%$ of the variance in benefits \& incentives were identified after rotation. They accounted for $61.6 \%$ of the total variance in benefits \& incentive satisfaction. Their communality estimates ranged from 0.4 to 091. Accordingly items from one to three are extracted under 
factor one and the remaining others under factor 2 .

Table 8. Factor loadings for rotated factors of benefits and incentives, DDU 2015/16.

\begin{tabular}{lllll}
\hline & & \multicolumn{2}{l}{ Factor Loadings } & \multirow{2}{*}{ Communality } \\
\cline { 3 - 4 } & & Factor 1 & Factor 2 & \\
\hline 1 & Payment scheme for extra work load & 0.84 & 0.435 & 0.91 \\
2 & Payment rate for extension and distance education & 0.73 & 0.47 & 0.75 \\
3 & Salary & 0.66 & & 0.56 \\
4 & Recognition for undertaking assigned committee task & & 0.86 & 0.91 \\
5 & Merit payments in the university & 0.63 & 0.64 & 0.80 \\
6 & Job security & & 0.52 & 0.40 \\
& Eigen values & 2.36 & 1.95 & \\
& Percentage of variance & 39.28 & 32.43 & \\
\hline
\end{tabular}

\subsubsection{Facilities}

As presented below (Table 9) four-factors which accounted for $27.37 \%, 18.74 \%, 19.2 \%$ and $16.4 \%$ of the total variance respectively were extracted. They accounted for $61.6 \%$ of the total variance in facility satisfaction. Their communality estimates ranged from 0.48 to 0.83 . Factor three and four constituted availability of computers and transportation facility respectively. Other items fall under factor one and two.

Table 9. Factor loadings for rotated factors of facilities, DDU 2015/16.

\begin{tabular}{|c|c|c|c|c|c|c|}
\hline & & \multicolumn{4}{|c|}{ Factor Loadings } & \multirow{2}{*}{ Communality } \\
\hline & & Factor 1 & Factor 2 & Factor 3 & Factor 4 & \\
\hline 1 & Availability of internet access & 0.87 & & & & 0.83 \\
\hline 2 & Availability of recreation facilities & 0.78 & & & & 0.70 \\
\hline 3 & Transportation facility & 0.56 & & & 0.60 & 0.81 \\
\hline 4 & Availability of repair and technical assistant & 0.61 & & & & 0.52 \\
\hline 5 & Availability of toilet rooms & 0.60 & & & & 0.51 \\
\hline 6 & Availability of office janitors & & 0.84 & & & 0.81 \\
\hline 7 & Availability of office furniture & & 0.69 & & & 0.62 \\
\hline 8 & Personal or shared office & & 0.56 & & & 0.48 \\
\hline 9 & Availability of computers for the academic staffs & & & 0.81 & & 0.68 \\
\hline \multirow[t]{3}{*}{10} & Availability of Stationary for teaching and learning & & & & & 0.24 \\
\hline & Eigen values & 2.73 & 1.87 & 1.92 & 1.64 & \\
\hline & Percentage of variance & 27.37 & 18.74 & 19.2 & 16.4 & \\
\hline
\end{tabular}

\subsubsection{Research Undertaking}

As presented in Table 10 below a total of four-factor solution provided the clearest extraction. These four factors accounted for about $72 \%$ of the total variance and communality estimates were fairly high for each of the 14 items with a range of 0.53 to 0.97 . After rotation the first, second, third and fourth factor accounted for $22.76 \%, 19.7 \%$, $15.62 \%$ and $13.99 \%$ of the variance respectively.

Table 10. Factor loadings for rotated factors of research undertakings, DDU 2015/16.

\begin{tabular}{|c|c|c|c|c|c|c|}
\hline & & \multicolumn{4}{|c|}{ Factor Loadings } & \multirow{2}{*}{ Communality } \\
\hline & & Factor 1 & Factor 2 & Factor 3 & Factor 4 & \\
\hline 1 & Availability of equipment for research (e.g. Laboratory...) & 0.79 & & & & 0.69 \\
\hline 2 & Research capacity building workshops & 0.69 & & & & 0.77 \\
\hline 3 & Time available to carry out your research duties & 0.66 & & & & 0.67 \\
\hline 4 & Availability of funds to attend professional conferences & 0.54 & & & & 0.64 \\
\hline 5 & Availability of research assistants & 0.5 & 0.47 & & & 0.67 \\
\hline 6 & Publication procedure & & 0.81 & & & 0.85 \\
\hline 7 & Publication opportunity & & 0.80 & & & 0.86 \\
\hline 8 & Importance attached to research for promotion & 0.40 & 0.51 & & & 0.67 \\
\hline 9 & Monitoring and evaluation of the projects & 0.44 & 0.49 & 0.43 & & 0.69 \\
\hline 10 & Number of research workshops in the university & & & 0.58 & & 0.53 \\
\hline 11 & Research and project proposal evaluation and approval & & & 0.53 & 0.50 & 0.63 \\
\hline 12 & Research and project financing procedure & & 0.44 & 0.52 & & 0.74 \\
\hline 13 & Strategic thematic areas identification procedure & & & & 0.88 & 0.97 \\
\hline \multirow[t]{2}{*}{14} & Research undertaking culture & & & 0.45 & 0.51 & 0.72 \\
\hline & Percentage of variance & 22.76 & 19.77 & 15.62 & 13.99 & \\
\hline
\end{tabular}




\subsubsection{Community Engagement}

As displayed below (Table 11) two-factors which accounted for $72.8 \%$ of the total variance in community engagement. After rotation factor one accounted for $36.75 \%$ and factor two accounted for $36.14 \%$ of the variance. Their communality estimates ranged from 0.48 to 0.83 . Hence items ranging from one to four are under factor one the remaining ones are under factor two. 'Follow up and support' has the highest loadings factor two and had a cross-loading over 0.4 on factor one.

Table 11. Factor loadings for rotated factors of community engagement, DDU 2015/16.

\begin{tabular}{|c|c|c|c|c|}
\hline & & \multicolumn{2}{|c|}{ Factor Loadings } & \multirow{2}{*}{ Communality } \\
\hline & & Factor 1 & Factor 2 & \\
\hline 1 & Community engagement culture in the university & 0.85 & & 0.83 \\
\hline 2 & Communication with local stakeholders to identify needs & $0 . .82$ & & 0.82 \\
\hline 3 & Thematic area identification procedure & 0.69 & & 0.62 \\
\hline 4 & Community engagement proposal evaluation and approval procedure & 0.61 & 0.49 & 0.60 \\
\hline 5 & Incentive and reward scheme for community engagement & & 0.83 & 0.82 \\
\hline 6 & Follow up and support given & 0.46 & 0.78 & 0.83 \\
\hline 7 & Importance attached to community engagement for promotion & & 0.72 & 0.63 \\
\hline \multirow[t]{3}{*}{8} & Community engagement financing procedure & 0.53 & 0.63 & 0.68 \\
\hline & Eigen values & 2.94 & 2.89 & \\
\hline & Percentage of variance & 36.75 & 36.14 & \\
\hline
\end{tabular}

\subsubsection{Interpersonal Relationship}

From a total of five items the extraction resulted in two factors where the first accounted for $36.88 \%$ and the second accounted for $27.24 \%$ of the variance in interpersonal relationship (Table 12). They accounted for $64.28 \%$ of the total variance and their communality estimates were fairly high for each of the 5 items with a range of 0.55 to 0.9 . The exception lies is the fifth item with the least communality estimate, 0.31 . Therefore the first three items fall under factor one and the other two items under factor two.

Table 12. Factor loadings for rotated factors of interpersonal relationship, DDU 2015/16.

\begin{tabular}{llll}
\hline & & \multicolumn{2}{l}{ Factor Loadings } \\
\cline { 3 - 4 } & & Factor 1 & Factor 2 \\
\hline 1 & Personal relationship with colleagues & 0.94 & 0.90 \\
2 & The academic communication among colleagues & 0.71 & 0.49 \\
3 & Support from colleagues for the activities you carry out & 0.62 & 0.41 \\
4 & Clerical support in your department & & 0.81 \\
5 & Support from administrative personnel outside your department & 0.74 & 0.52 \\
& Eigen values & 1.84 & 0.71 \\
& Percentage of variance & 36.88 & 0.31 \\
\hline
\end{tabular}

\subsubsection{University's Management}

It can be seen below (Table 11) that from a total of six items two factors which accounted for $72.8 \%$ of the total variance in university's management were identified. After rotation factor one accounted for $38.48 \%$ and factor two accounted for $33.97 \%$ of the variance. Their lowest and highest communality estimates were 0.54 and 0.88 respectively. Hence items ranging from one to three are under factor one and the others under factor two.

Table 13. Factor loadings for rotated factors of university management, DDU 2015/16.

\begin{tabular}{llll}
\hline & & Factor Loadings & Factor 2 \\
\cline { 3 - 4 } & & Factor 1 & 0.92 \\
2 & Communication between university management staff & 0.91 & 0.88 \\
3 & Quality of leadership in the university & 0.67 & 0.84 \\
4 & Quality of administrative staffs & & 0.54 \\
5 & Yourport you get from your department head & & 0.86 \\
6 & Quality of leadership in the department & 0.83 & 0.70 \\
& Eigen values & 2.31 & 0.58 \\
& Percentage of variance & 38.48 & 2.04 \\
\hline
\end{tabular}

\subsection{General Satisfaction Across Sex}

As the result presented in Table 14 below revealed that the general mean satisfaction of academic staff is higher for teaching-learning, interpersonal relationship and with the management of the university where as facilities drive the lowest satisfaction. Sex wise disaggregation indicated that male staff have highest mean satisfaction from interpersonal relationship and teaching-learning. Similarly female drive their better mean satisfaction from their interpersonal 
relationship and management of the university which could be form the fact that the university has placed different women empowerment schemes.

Table 14. Mean satisfaction of the staff across sex, DDU 2015/16.

\begin{tabular}{lllll}
\hline & & \multicolumn{2}{l}{ Mean satisfaction } & General \\
\cline { 1 - 1 } & & Male & Female & satisfaction \\
\hline 1 & Teaching-learning & 3.3 & 3.47 & 3.33 \\
2 & Facilities & 2.52 & 3.02 & 2.59 \\
3 & Benefits and incentives & 2.53 & 3.13 & 2.64 \\
4 & Research undertakings & 2.7 & 3.10 & 2.75 \\
5 & Community engagement & 2.76 & 3.06 & 2.79 \\
6 & $\begin{array}{l}\text { Academics' interpersonal } \\
\text { relationship }\end{array}$ & 3.45 & 3.86 & 3.51 \\
\multirow{2}{*}{7} & $\begin{array}{l}\text { Management of the } \\
\text { university }\end{array}$ & 3.18 & 3.52 & \multirow{2}{*}{3.26} \\
\hline
\end{tabular}

Michael O. S. conducted a study in South Africa on attrition and retention of academic staff in higher institutions. It incorporated academic staff from ten universities and found that respondents place greater importance on challenging work, inter-personal relationship, access to research resources and job security. Results are discussed in terms of the implications for retention practices in the universities [21]. In terms of benefits and incentives several studies have shown that academic staff satisfaction is highly influenced by their pay that either salary of payments related to other works [15] [19]. Additionally a study conducted in Pakistan found that compensation and job insecurity have significant impact on the academic staff of both private and public higher education institutions [12] [22]. Another factor that was found to have significant impact on academic staff satisfaction is promotion. A study found that promotion which is due to either to teaching-learning, research undertakings and community engagement are found to highly influence staff satisfaction [23] [24].

\section{Conclusion and Recommendations}

Education sector is one of the service sectors that having a great demand in present day context and it has been considered as a business, which practices all the theories and concepts related to any other business. The concept of job satisfaction has become the essential feature that organizations do evaluate the satisfaction either their employees or their customers on a regular basis. This study focused on and evaluated the satisfaction level of academic staff in the university. The result of the data from the questionnaire and interview indicate that the satisfaction level of the Academic staff is nearly $40 \%$. From this it was concluded that the satisfaction level for the academic staff is moderate though it increased from the satisfaction level of the same group found in the previous year (2014/15). In general, the study reveal the average satisfaction level of the academic staff is better on teaching-learning, interpersonal relationship and management of the university where as the least satisfaction comes from the facility of the university. It could be concluded that service quality of Dire Dawa University shows progress but the management and other stakeholders of the university should focus and work on improving the facilities including recreation provision, internet access, transportation facility and restrooms on buildings. Additionally various equipment required by researchers should be made available on timely basis and support to fund attendance of professional conference should be increased.

\section{References}

[1] GebrekirosHagos, Kebede Abrha (2015). Study on factors affecting Job Satisfaction in Mekele University Academic staff at Adi-Haqi campus. International Journal of Scientific and Research Publications, Volume 5, Issue 1.

[2] Abosede, Subuola Catherine and Ago-Iwoye (2014). Gender Differences in Job Satisfaction of Academic and NonAcademic Staff of Olabisi Onabanjo University, AgoIwoye, Ogun State, Nigeria. Journal of Education and Practice, Vol.5, No.22.

[3] Mumford, E. (1991). Job satisfaction: A method of analysis. Personal Review, 20(3), 11-19.

[4] Parasuraman, A., Zeithaml, V. and Berry, L. L., 1985, “ $A$ conceptual model of service quality and its implications for future research", Journal of Marketing, Vol. 49, autumn, pp. 41-50.

[5] Parasuraman, A., Zeithaml, V. and Berry, L. L., 1988, "SERVQUAL: a multiple-item scale for measuring consumer perceptions of service quality", Journal of Retailing, Vol. 64.

[6] Smith, G, Smith, A \& Clarke, A., 2007, evaluating service quality in universities: a service department perspective. Quality Assurance in Education, 15 (3):344- 351.

[7] MoE, 2009, "Education statistics annual abstract", Addis Ababa: Education sector Development programme planning and analysis department.

[8] UNICEF, 2014: Briefing Notes, Media and External Relations Section and Education Section www.unicef.org/ethiopia (Accessed on $23^{\text {rd }}$ April, 2016).

[9] Fulford, C., Zhan, S. (1993), Predicting Student Satisfaction from Perceptions of Interaction in Distance Learning, IFIP Transactions A: Computer Science and Technology No. A-29: 259-268.

[10] Huntley, J., Academic Evaluation and Grading: An Analysis and some Proposals, Harvard Educational Review, 46(4): 612631 (1976).

[11] Siddiqui, A. \& Saba, I. (2013). Determining the Job Satisfaction Level of the Academic Staff at Tertiary Academic Institutes of Pakistan. International Journal of Information, Business \& Management, 5(3), 42.

[12] Noordin, F. \& Josuff, K. (2009). Levels of Job Satisfaction amongst Malaysian Academic Staff. Asian Social Science, 5(5), 122-128.

[13] Santhapparaj, A. S. \& Alam, S. S. (2005). Job Satisfaction among Academic Staff in Private Universities in Malaysia. Journal of Social Sciences, 1(2), 72-76.

[14] Smith, P. C., Kendall, L. M. \& Hulin, C. L. (1969). Measurement of Satisfaction in Work and Retirement. Rand McNally, Chicago, IL. 
[15] Lacy, F. J. \& Sheehan, B. A. (1997). Job Satisfaction among Academic Staff: An International Perspective. Higher Education, 34, 305-322.

[16] Andreasen, T. \& Lindestad, B. (1998). Customer loyalty and complex services. International Journal of Service Industry Management, 9, 7-23.

[17] Sokoya, S. K. (2000). Personal Predictors of Job Satisfaction for the Public Sector Manager: Implications for Management Practice and Development in a Developing Economy. Journal of Business in Developing Nations, 4(1).

[18] Cochran (1977). Sampling Techniques $3^{\text {rd }}$ edition. John \& Wiley Sons Inc., NewYork.

[19] Michael O. Samuel and Crispen Chipunza (2013). Attrition and Retention of Senior Academics at Institutions of Higher
Learning in South Africa: The Strategies, Complexities and Realities.

[20] Saba, I. \& Zafar, O. (2013). Analyzing Job Satisfaction Level of the Academic Staff: A Case Study of Public and Private Universities of Punjab, Pakistan. International SAMANM Journal of Marketing and Management, 1(2).

[21] Ellickson, M. C. \& Longsdon, K. (2002). Determinants of Job Satisfaction of Municipal Government Employees. Public Personnel Management, 31(3), 343-358.

[22] Arnold, H. J. \& Feldman, D. C. (1996). Organizational Behavior. McGraw Hill.

[23] Agus Munandar (2015). Participatory Performance Measurment or Self-Assessment: Amerlioration Employee Job Satisfaction. 